Article

\title{
Interculturalism and Physical Cultural Diversity in the Greater Toronto Area
}

\author{
Yuka Nakamura ${ }^{1, *}$ and Peter Donnelly ${ }^{2}$ \\ ${ }^{1}$ School of Kinesiology and Health Science, York University, Toronto, M3J 1P3, Canada; E-Mail: nakamura@yorku.ca \\ 2 Faculty of Kinesiology and Physical Education, University of Toronto, Toronto, M5S 2W6, Canada; \\ E-Mail: peter.donnelly@utoronto.ca \\ * Corresponding author
}

Submitted: 30 January 2017 | Accepted: 20 April 2017 | Published: 29 June 2017

\begin{abstract}
The Greater Toronto Area (GTA) is one of the most multicultural communities in the world. Frequently, this description is based on ethnic, linguistic, and culinary diversity. Physical cultural diversity, such as different sports, martial arts, forms of dance, exercise systems, and other physical games and activities, remains ignored and understudied. Based on a living database of the GTA's physical cultural diversity, this study identifies the trajectories of the lifecycle of activities that have been introduced into the GTA's physical culture by immigrants. These pathways differ based on whether the activity is offered in a separate setting, where individuals may be participating with other immigrants of the same ethnocultural group, or mixed settings, where people are participating with people from outside of their ethnocultural group. We argue that the diversity and the lifecycle trajectories of physical cultural forms in the GTA serve as evidence of interculturalism and the contribution by immigrants to the social and cultural life of Canada.
\end{abstract}

\section{Keywords}

diversity; immigrants; interculturalism; physical culture; sport; Toronto

\section{Issue}

This article is part of the issue "Sport for Social Inclusion: Questioning Policy, Practice and Research", edited by Reinhard Haudenhuyse (Vrije Universiteit Brussel, Belgium).

(C) 2017 by the authors; licensee Cogitatio (Lisbon, Portugal). This article is licensed under a Creative Commons Attribution 4.0 International License (CC BY).

\section{Introduction}

According to the 2011 National Household Survey, 20.6\% of the population was born outside of Canada. Indeed, over 200 different ethnic groups are represented in Canada (Statistics Canada, 2016). In the Greater Toronto Area (GTA) alone, it is estimated that by 2031 approximately $75 \%$ of people living in the GTA will be immigrants or Canadian-born children of immigrants (Statistics Canada, 2010). It is not surprising then that the GTA is viewed as one of the most multicultural communities in the world, with its ethnic, linguistic, and culinary diversity. Interestingly, with the exception of dance, physical cultural diversity is not often included in this list. Indeed, physical cultural diversity, such as different sports, martial arts, forms of dance, exercise systems, and other physical games and activities, remains understudied.

The GTActivity study is the first attempt to document the diversity of physical culture in a large and extremely multicultural community. Based on this study, we identify the main trajectories of the lifecycle of activities that have been introduced by immigrants into the physical culture of the GTA. These pathways differ based on: whether the activity is offered in a separate setting, where individuals may be participating with other immigrants of the same ethnocultural group; or mixed settings, where people are participating with individuals outside of their ethnocultural group. We argue that the diversity and the lifecycle trajectories of physical cultural forms in the GTA shed light on the role of sport in promot- 
ing multiculturalism, intercultural understanding, and social inclusion in its broadest sense-sport offers a way to contribute to the social and cultural life of Canada, and increases access to and participation in sport for all.

In Canada, social inclusion must be understood in relation to the Multiculturalism Act, the fundamental principles of which are that all citizens may maintain their identities; share and take pride in their cultural traditions and have a sense of belonging in the nation; and that all citizens should have the opportunity to participate in Canada's cultural and civic life, irrespective of ethnicity or ancestry. The Canadian Government calls this "inclusive citizenship" (Government of Canada, n.d.). It has been claimed though that multiculturalism has failed, and other terms, such as interculturalism, have been offered as an alternative. Interculturalism has multiple definitions, but fundamentally, emphasises dialogue and interaction between people who are different (e.g., Donnelly \& Nakamura, 2006; Frisby, 2014; Henry, Amara, \& Aquilina, 2007; Meer \& Modood, 2012). We concur with Meer and Modood (2012) that interculturalism has valuable features, many of which are foundational to multiculturalism. Thus, in this paper we focus on the role of sport specifically to promote interculturalism, not as an alternative to, but as a form of multiculturalism.

\section{Review of Literature}

Research on the intersection of sport, physical activity, and ethnicity can be divided into four broad categories based on the general approach taken to understanding immigration and settlement processes. The first is the assimilation model and the related acculturation framework, whereby sport and physical activity are seen as vehicles for integration into the broader society (e.g., Allen, Drane, Byon, \& Mohn; 2010; Donnelly \& Day, 1981; Hofmann, 2008; Lee \& Funk, 2011).

The second approach involves resistance to assimilation. This position argues that ethnic groups resist pressures to assimilate and maintain ethnic consciousness through sport (e.g., Allen et al., 2010; Krouwel, Boonstra, Duyvendak, \& Veldboer, 2006; Ricatti \& Klugman, 2013). This can be further divided into two sub-categories. On the one hand, ethnic identity may be primordial and sport and physical activity are used to maintain this identity in the face of assimilative pressures. On the other hand, ethnic consciousness may be a reaction to discrimination or other forms of marginalization; this identity is also known as reactive ethnicity.

The third category of research (barriers model) focuses on identifying barriers to full participation in physical culture. The barriers can be economic, or stereotypes held by sport providers (e.g., Taylor \& Toohey, 1998; Toohey \& Taylor, 1997). While important, this approach could have implicit assimilationist undertones or introduce a cultural deficit explanation, whereby it is assumed that the beliefs of the cultural group are the obstacles to sport participation.
There is a tendency in these three categories of research to view culture and identity as homogeneous and static. In contrast, the fourth category of research takes a more dynamic view of ethnic identity and recognizes the contextual, shifting, and multiplicity of identity (e.g., Burdsey, 2010; Erueti \& Palmer, 2014; Hofmann, 2008; Nakamura, 2012; Raman, 2015; Ricatti \& Klugman, 2013; Tirone, 2001). What becomes clear in this research is the agency and resourcefulness of ethnic groups to participate on their own terms, often in the face of ongoing racism (e.g., Nakamura, 2012; Thangaraj, 2013, 2015a, 2015b; Tirone, 2001; Tirone \& Pedlar, 2000). One such example is participation in sport clubs that are organized along ethnic lines. These activities may be the traditions of a particular group, or they may be globalized and/or traditionally 'Canadian' sports organized by and for members of a specific group.

In fact, there is growing scholarly interest in these separate and mixed sport clubs (e.g., Chin, 2012; Nakamura, 2012; Thangaraj, 2013, 2015a, 2015b; Willms, 2010). Among this work, the literature examining European contexts such as Norway, Holland and Belgium (e.g., Theeboom, Schailée, \& Nols, 2012; Vermeulen \& Verweel, 2009; Walseth, 2016) frequently examine how much bridging and bonding forms of social capital (Putnam, 2000) are accrued through involvement in separate versus mixed clubs. While interesting, these cases offer just a snapshot of participation and ultimately take a functionalist approach, treating sport as a medium to achieve other goals. Limited value is placed on the experience of sport or on sport in and of itself. Furthermore, while there is recognition that these clubs are diverse internally, how the clubs and their membership change over time remains unknown. Therefore, this paper refines our understanding of participation in physical culture that is organized in mixed and separate settings in Canada by examining the diversity of physical culture practiced in the GTA, and identifying the lifecycle and patterns of participation in these different activities.

\section{Methodology}

This paper draws on data collected by undergraduate students enrolled in an upper year, university course directed by the second author. Student research teams were given an assignment that entails selecting a physical cultural activity practiced among the numerous ethnic groups within the GTA. They recruited and interviewed three key informants who participate in the activity and who identify with the ethnic group with which the activity is associated. The interviewees were asked if the activity is limited to the ethnic group, whether those outside of the ethnic group were recruited to participate, and their assessment of whether the activity was spreading beyond their particular ethnic community. Course work ethics approval was received from the university research ethics board for each year that the assignment was administered. Data have been collected 
annually since 1998 with the exception of when the course was not offered. More systematic data collection began in $\mathbf{2 0 1 6}$ with the launch of the GTActivity website (htts://gtactivity.ca); research assistants have been collecting data with ethics approval from the University of Toronto research ethics board.

\section{Results: Lifecycle of Physical Cultural Forms}

Student researchers and research assistants have thus far (January, 2017) identified over 650 different physical cultural activities (some 300 of which are currently listed on https://gtactivity.ca). Based on the data collected, and supplemented with academic literature, we identify at least five trajectories for the forms of physical culture that have been introduced to and are practiced within the GTA by immigrant communities (see Table 1).

By generation, we are not referring to the generation of immigration (i.e., $1^{\text {st }}, 2^{\text {nd }}, 3^{\text {rd }}$ generation immigrants). Rather, the term refers to the generation of participants (i.e., rookies, veterans, alumni). Following previous research on separate and mixed sport clubs, we have used, for the most part, the same terms to delineate the different trajectories. Separate participation refers to engagement in the activity with individuals who are of the same ethnic or cultural background, and/or that involvement in the activity remains within the community with which it is associated. Mixed refers to participation in an activity that goes beyond the ethnic or cultural community of origin. While we recognize that individuals are multifaceted and that even an ethnically exclusive and separate activity, can be inclusive of participants of diverse genders, social class backgrounds, language, and so on, for the purposes of this framework of the lifecycle of physical cultural activities, we are focusing specifically on opportunities that, in keeping with previous research, are separate and mixed in terms of ethnicity.

Not included in this framework are those activities that were not 'brought to' and/or not practiced by newcomers to Canada. This may be because the activities require specific equipment or particular spaces in which to participate. Other practices may be considered culturally inappropriate. The following discussion provides details of and examples for each trajectory.

\subsection{Separate Participation by First Generation of Players $\rightarrow$ Decline and Virtual Disappearance of the Sport}

Examples of activities that were exclusively engaged in by one generation of players include hurling, pessapallo, korfball, bandy, and eisstock. There are likely a number of reasons ranging from intentional exclusion to ethnic maintenance as previous research has noted. It may also be that there were sufficient numbers to engage in the activity or there was no commercial imperative to attract participation of others.

For various reasons, the sports cease to be meaningful to others, such that a second generation of players does not emerge. For example, these individuals may be more integrated and socialized into 'Canadian' physical culture through participation in schools and communities (Doherty \& Taylor, 2007; Institute for Canadian Citizenship [ICC], 2014), or the first generation of players may have also embraced Canadian culture, such that they did not continue or attempt to pass on some specific cultural forms to others. There are certainly exceptions to this, such as racism and other barriers that preclude access to other sports (e.g., Doré, 2002; Thangaraj, 2013, 2015a, 2015b; Tirone, 2001), as well as the added complexity of feeling compelled to take up aspects of 'Canadian' physical culture (ICC, 2014). Some sports and games (including folk games) may survive, or only appear during family and community celebrations. Furthermore, the trajectory of a particular activity may be unique to the GTA, as eisstock has a number of participants in Kingston, approximately $265 \mathrm{~km}$ east of the GTA, and Kitchener, some $80 \mathrm{~km}$ west of the GTA.

\subsection{Separate Participation by First Generation of Players $\rightarrow$ Decline and Virtual Disappearance of the Sport $\rightarrow$ Revival of Participation}

Some activities become quite well established, decline for the reasons noted above, and are then revived by a

Table 1. Trajectories of physical culture in the GTA.

\section{Generation of Players}

\begin{tabular}{llr}
\hline $1^{\text {st }}$ & $2^{\text {nd }}$ & New $1^{\text {st }}$ or $3^{\text {rd }}$ \\
\hline Separate $\rightarrow$ & Decline and disappear & Revival \\
Separate $\rightarrow$ & Decline and disappear $\rightarrow$ & - Exclusive \\
& & - Inclusive \\
\hline Separate $\rightarrow$ & & Mixed $\rightarrow$ \\
\hline Mixed $\rightarrow$ & Mixed $\rightarrow$ & Mixed $\rightarrow$ \\
\hline Mixed $\rightarrow$ & Mixed $\rightarrow$ & Semi-Mixed $\rightarrow$ \\
\hline
\end{tabular}


new generation of immigrants. For example, economic problems in Ireland in the mid 2000s led to a new wave of young Irish immigrants to the GTA, and to the revival of games that had declined (e.g., Gaelic football) or 'died out' in the GTA in the 1980s (e.g., hurling and camogie). Likewise, rugby league declined after the 1930s and 1940s, but has since experienced a revival from the 1980s onward. Other activities are declining in participation within the community, though they may experience a revival; these include korfball, Korean folk dance, and Lithuanian folk dance. However, activities such as Balinese dance and kendo are both experiencing a decline among Indonesian- and Japanese-Canadians respectively, but have growing interest from outside of these communities. In the case of cricket, Joseph (2016) observed a decline in participation in cricket in the Caribbean community, but a simultaneous growth in South Asian communities, one that is influenced by a number of factors, including increasing migration of individuals from South Asian countries and the restrictions placed on migration from Caribbean nations.

\subsection{Separate Participation by the First Generation $\rightarrow$ Inclusive Participation by Subsequent Generations of Players}

A third trajectory involves separate participation (be it informally or codified into rules/regulations) that later becomes increasingly inclusive of people of different ethnic backgrounds. Examples include various martial arts (from China, Japan, Korea, and Brazil) and Chinese 9-man volleyball. Others may seek out the activities because they are seen as novel and meaningful. Or participants may reach out to other communities for various reasons. For example, there may be a rational attempt to improve the quality of a team, such as in the case of Chinese 9-man volleyball (Nakamura, 2009) or globalized sports such as soccer, rugby or cricket (e.g., Donnelly \& Day, 1981). There may be commercial motivations, such as opening schools and teaching others, as in the case of capoeira (Joseph, 2005). Recruiting from other communities may be an attempt to ensure the survival of some of the activities noted in the previous trajectory (e.g., Gaelic football). Survival may also entail a strategy of inclusion where there are not enough potential players in the ethnic community in order to establish competitions. Australian Rules football in the GTA had previously required that a minimum number of players originally from Australia must be included on each team. Now, the rules require 16 of the 24 players be Canadian. It should be pointed out that even if sponsoring groups and team names continue to reflect particular ethnic affiliations, members might be drawn from different backgrounds. The North American Chinese Invitational Volleyball Tournament, for example, includes participation of non-Chinese players and even has codified rules listing the other groups that may participate (Nakamura, 2009), and the name of the championship tournament remains unchanged. Karlis's (2015) study of a Greek ice hockey league based in Ottawa, Canada, showed that it was originally separate, with exclusive participation for people of Greek decent. However, due to changing demographics, teams found themselves unable to recruit enough players of Greek descent for a team or tournament, and thus, rules were relaxed to permit players who were associated with the Greek community by blood or by friendship. Thus, while the name remains unchanged and the league still privileges Greek ethnicity, participation is mixed.

\subsection{Mixed Participation by First Generation and Beyond}

Activities that were inclusive from their arrival in Canada include Aussie Rules football, kabbadi, and various martial arts and dance forms. The reasons given for this, based on interviews with GTA based clubs and teams, include the need for participants to ensure competitions (e.g., Aussie Rules football, as noted above); embracing the principles of multiculturalism and wishing to share a cultural activity with other Canadians (e.g., kabbadi); and for commercial purposes (e.g., some martial arts such as capoeira).

\subsection{Mixed Participation by the First Generation $\rightarrow$ Semi-Mixed Participation}

We identified a number of examples (both in the data and in the literature) where participation was originally mixed (i.e., primarily globalized sports such as soccer) and then became more separate, in that a parallel opportunity to participate forms and flourishes. This seems to occur for different, but sometimes connected reasons. Communities may develop the organizational capacity, infrastructural know-how (e.g., how to rent public recreational spaces, access referees and officials, and so on), and enough interested individuals within the community to organize their own activities, activities that they had previously accessed through mainstream, mixed clubs and organizations. There may also be related feelings of dissatisfaction with the available mixed organizations, and/or feelings of exclusion in, or from, those organizations. Further, the parallel organizations may be better able to accommodate the needs of a group. A Muslim soccer association in the GTA, for example, does not schedule games during the month of Ramadan when many of the participants are fasting.

It should be noted that the ethnocultural communities forming their own organizations are themselves not homogeneous. For example, a South Asian organization may include participants from Pakistan, India, Sri Lanka, and Bangladesh (all of which also have regional, linguistic and religious divisions), so there is still inclusion beyond a specific regional/linguistic/religious community. Indeed, even if a team, league or tournament is organized along ethnic lines, participation may facilitate crossing other boundaries, such as clan or locality (Spaaij, 2015) or fostering loyalties to other forms of community 
such as hometown, nation or diaspora, as in the case of Chinese 9-man volleyball (Nakamura, 2016).

\section{Discussion}

The trajectories outlined above illustrate that the contexts in which people participate in various physical cultural forms change over time. Involvement may begin with playing, exercising or competing with people who are of the same ethnicity, in an activity that is closely tied to one's ethnic or cultural group. However, over time and in response to various circumstances (i.e., competitiveness, lack of players, commercial needs), this may change or expand. Thus, where in the first instance one might conclude that individuals are maintaining their ethnic identities and using physical culture to strengthen their communities, when participation changes to include individuals from outside of the community or to consist of other similar but nonetheless 'new' activities, then it becomes more complicated. The dynamic and multiple identity approach to the study of physical culture among ethnic groups is more flexible than previous frameworks because it can account for participation that is both in separate and mixed settings, without drawing conclusions about assimilation or ethnic maintenance.

Without discounting the role that physical culture may continue to play in building, maintaining, and protecting community, the more dynamic approach to understanding identity better reflects the reality of the lives, identities, and physical cultural practices of immigrants and ethnic and visible minority people in Canada. Many 'new Canadians' want to participate in aspects of 'Canadian' culture and to maintain aspects of their ethnic identities (ICC, 2014). For example, individuals may be involved in a number of sporting activities, such as baseball in the summer and ice hockey in the winter, or playing basketball and korfball at their Dutch family picnic, or playing hockey in the winter and pessapallo with their Finnish community in the summer. As the results of this study suggest, involvement in a particular activity and with a specific group can shift over time, with the boundaries of participation expanding or shrinking for various reasons. It is beyond the scope of this paper to assess whether it is shifting identities that allow for greater flexibility in defining who may participate, or whether the shift to more mixed participation in response to external factors helps to foster more dynamic definitions of belonging. Nevertheless, the different trajectories and the changes in participation over time, are indicative of the instability of identity.

Interestingly, we did not discover any sports, in the literature or in interviews, that were organized on ethnoculturally exclusive lines for more than one generation or so, except for some private golf and curling clubs that historically based their membership on racial/ethnic and religious exclusion. Our data show, for instance, that for the most part, the activities that continue are ones that are mixed and inclusive of individuals who may not necessarily identify with the activity's community of origin. This finding could be interpreted as successful integration or acculturation; however, decisions to expand definitions of who may participate, who belongs, who is a member, and so on, are influenced by social, cultural and/or other forces. How we participate in physical culture and the role that identity plays in these decisions, therefore, cannot be captured by a unidirectional journey that ends with integration, acculturation or assimilation. For instance, it is entirely possible that individuals may play the same sport for a separate, ethnic club and mixed, representative teams (e.g., soccer for an intercollegiate or provincial team); or play both mainstream and ethnically identified sports at competitive levels (e.g., volleyball and Chinese 9-man volleyball; wrestling and kabbadi). Such participation has been seen in previous research (e.g., Nakamura, 2009, 2016) but is not captured in studies that examine separate and mixed sport opportunities and their role in building social capital for participants (e.g., Theeboom et al., 2012; Vermeulen \& Verweel, 2009; Walseth, 2016) because they are usually taking a snapshot of participation, and may not necessarily account for how participation and opportunities change over time. Indeed, Vermeulen and Verweel's (2009) conclusion that "both separate and mixed sport clubs create contexts for the formation of social networks, for the development of norms of reciprocity and the generation of social trust" (p. 1210), may reflect the fluidity of identity and the flexibility with which individuals seek out and organize physical cultural opportunities.

\section{Conclusion}

The main findings of this study are (1) a very diverse repertoire of physical cultural activities is currently being practiced in the GTA; (2) these activities have different life cycle patterns; and (3) the life cycles of participation in an activity may be influenced by social, cultural and other external factors. Together, these findings have implications for our understanding of social inclusion.

In a Canadian context, social inclusion is discussed predominantly in terms of multiculturalism. Nevertheless, multiculturalism has been criticized particularly with regard to the notion of celebrating difference. Specifically, in Canada: "Liberal multiculturalism has taken a 3-D approach-one that celebrates dance, dress, and dining, but fails to take into account the multiple dimensions of racial and social inequality" (Srivastava, 2007, p. 291). Furthermore, groups and their cultures are treated as unchanging and static, which in turn reinforces difference and Otherness. Indeed, one could argue that the diversity of physical cultural forms available in the GTA is precisely because celebrating these types of difference is far more palatable than other forms of difference, and this study could unintentionally reproduce this emphasis on and depoliticizing of difference.

Kymlicka (2010) acknowledges that 3D critiques of multiculturalism and that ethnocultural groups and their 
traditions may be trivialized or marginalized. He also agrees that such othering should be resisted. However, Kymlicka (2010) rejects the claim that the 3D model of multiculturalism is an explicit purpose of multiculturalism policies, stating that multiculturalism "has never been exclusively, or even primarily, about inculcating such an ethos of cultural consumption" (Kymlicka, 2010, p. 99). Instead, multiculturalism policies have focused in part on constructing new forms of citizenship for immigrants (Kymlicka, 2010). Similarly, George Elliott Clarke argues that, "Canada is still not yet a truly egalitarian, multiracial and multicultural state. But multiculturalism, even in its liberal, statist guise, has been a positive step forward. It has served-and can serve-to expand the inclusive sense of the term Canadian" (2009, p. 5).

Sport, in particular, has played a role in 'citizenization' (Kymlicka, 2010) or citizen-building, with both empowering and disempowering effects and intentions. For example, sport and physical education have functioned as key vehicles for the production of robust and vital citizens who in turn reflect a likewise robust and vital nation (McNeill, Sproule, \& Horton, 2003; Nakamura, 2012; Okay, 2003). Excelling at international sporting events affords an opportunity to display this symbolic power in a legitimate and sanctioned manner (Nakamura, 2012). While this citizenship- and nation-building capacity of sport has been mobilized for colonial and neocolonial endeavours that reinforce hierarchies and social exclusion, the potential for sport to promote citizenship, when defined in inclusive and transformative ways, offers a chance to promote the kind of citizenization that Kymlicka (2010) envisions. As Bakht suggests, "the 'song and dance' aspect of multiculturalism could have a profound effect on reshaping preconceived notions of difference" (2011, p. 7). Following Kymlicka's (2010) lead, then, we suggest that the diverse forms of physical culture being practiced, are evidence of citizenization because ethnic groups are contributing to the fabric of Canadian society.

Sport is uniquely positioned to foster citizenization as a result of a widespread belief that it may serve as an instrument for social inclusion by crossing all borders and helping to bring people together. International policies and programs reflect this belief (see, for example, Becker et al., 2000; PMP \& Institute of Sport and Leisure Policy, 2004). Even the inaugural report produced by the ICC focused on the view of sport among newcomers and recent immigrants and the role that sport plays in their integration and inclusion (ICC, 2014). In fact, the ICC study demonstrates that recent immigrants identify ice hockey as a way to become Canadian because to know about hockey was framed as a way to gain acceptance. However, one participant went as far as to say that "if I am nonhockey, then I am nowhere" (ICC, 2014, p. 22), illustrating the value that is placed upon hockey in a Canadian context, and in turn, the lack of value (and relatedly, lack of resources, space, and opportunity) that may be given to other activities. This particular finding illustrates the complexity of social inclusion through sport because belong- ing may be claimed and conferred (see also Spaaij, 2015) only for activities that align with and celebrate existing social norms. The meaning of participation in sport or any physical cultural practice is clearly shaped by the broader social context. This complexity and the ways in which people navigate, negotiate, and resist dominant physical cultural forms, and make room for their own diverse practices, is an area that requires additional research using qualitative methodologies such as ethnography to provide rich, narratives of the meanings of physical cultural participation, and its role in inclusion and belonging.

While participation in sport and physical culture should not be seen as a panacea, physical culture nonetheless, could be a way to promote liberaldemocratic citizenship, and to transform relationships between minority groups and the state, and between members of different groups, as outlined by Kymlicka (2010). As Phillips, Athwal, Robinson and Harrison (2014) note, there is an increasing focus on everyday intercultural exchanges that occur at the local, neighbourhood level, interactions that may facilitate improved social relations. These encounters are usually centred around shared community- or neighbourhood-level concerns. Wenger (1998) argues that convergence around common interests and goals can lead to social interaction, cooperation, intercultural learning, and ultimately, the development of 'communities of practice.' Clearly, physical culture could serve as a point of convergence, and our data suggest that it has occurred to varying degrees. Furthermore, the diversity of physical cultural forms offers casual and structured opportunities, both of which have been found to potentially foster connections across different groups (Amas \& Crosland, 2006, as cited by Phillips et al., 2014).

Whether a shared interest in a physical cultural form leads to sustained bridging capital is beyond the scope of this study. However, evidence that mixed physical culture opportunities are more sustainable suggests that this may be the case. Instead, we wish to highlight the importance of being able to add to the cultural and social life of Canada. This opportunity to contribute should be fostered and protected, for in doing so, interculturalism, or the exchange of ideas, dialogue across difference, and the synthesis of something new, becomes a real possibility.

\section{Acknowledgements}

The authors acknowledge the contributions of students who were enrolled in PE/KIN 3 P03 at McMaster University and PHE 301 at the University of Toronto. The authors gratefully acknowledge a research contract with Multiculturalism Canada and Sport Canada that helped to fund an earlier phase of this research; and a Social Sciences and Humanities Research Council Insight Grant \# 862-2012-0003, funded through the Sport Canada Sport Participation Research Initiative that is supporting the current phase of this research. In addition to the authors, 
the co-applicants and collaborators include P. Safai, B. Kidd, D. Burdsey, M. VanBottenburg, and T. Taylor.

\section{Conflict of Interests}

The authors declare no conflicts of interests.

\section{References}

Allen, J. T., Drane, D. D., Byon, K. K., \& Mohn, R. S. (2010). Sport as a vehicle for socialization and maintenance of cultural identity: International students attending American universities. Sport Management Review, 13(4), 421-434.

Bakht, N. (2011). Mere "song and dance": Complicating the multicultural imperative in the arts. In M. Chazan, L. Helps, A. Stanley, \& S. Thakar's (Eds.), Home and native land: Unsettling multiculturalism in Canada. Toronto: Between the Lines.

Becker, P., Brandes, H., Kilb, R., Opper, E., Stolz, H., Vestweber, K., . . . \& Jeglitza, M. (2000). European Union study on sport as a tool for the social integration of young people. Final report for the European Commission. No. 1999-0458/001-001 SVESVE4ET. Retrieved from http://www.isca-web.org/ files/EU\%20Documents/Sport\%20as\%20a\%20Tool\% 20for\%20Social\%20Integration\%20of\%20young\%20 People.pdf

Burdsey, D. (2010). British Muslim experiences in English first-class cricket. International Review for the Sociology of Sport, 45(3), 315-334.

Chin, C. B. (2012). Hoops, history and crossing over: Boundary making and community building in Japanese-American basketball leagues (Unpublished dissertation). University of California, Los Angeles.

Clarke, G. E. (2009). Multiculturalism and its (usual) discontents. Canada Watch, Robarts Centre for Canadian Studies, York University. Retrieved from http:// www.yorku.ca/robarts/projects/canada-watch/multi cult/pdfs/Clarke.pdf

Doherty, A., \& Taylor, T. (2007). Sport and physical recreation in the settlement of immigrant youth. Leisure/Loisir, 31(1), 27-55.

Donnelly, P., \& Day, R. D. (1981). Ethnic soccer clubs in London, Canada. A study in assimilation. International Review of Sport Sociology, 16(1), 37-52.

Donnelly, P., \& Nakamura, Y. (2006). Sport and multiculturalism: A dialogue. Toronto: University of Toronto.

Doré, A. (2002). Japanese-Canadian sports history in the Fraser Valley: Judo and baseball in the interwar years. Journal of Sport History, 29(3), 439-456.

Erueti, B., \& Palmer, F. R. (2014). Te Whariki Tuakiri (the identity mat): Maori elite athletes and the expression of ethno-cultural identity in global sport. Sport in Society, 17(8), 1061-1075.

Frisby, W. (2014). Moving from multiculturalism to interculturalism through leisure. Annals of Leisure Research, 17(4), 354-358.
Government of Canada. (n.d). Canadian multiculturalism: An inclusive citizenship. Retrieved from http:// www.cic.gc.ca/english/multiculturalism/citizenship. asp

Henry, I., Amara, M., \& Aquilina, D. (2007). Multiculturalism, interculturalism, assimilation and sports policy in Europe and their relationship to sports policy. In I. Henry \& Institute of Sport and Leisure Policy (Eds.), Transnational and comparative research in sport: Globalisation, governance and sport policy (pp. 115-143). London: Routledge.

Hofmann, A. R. (2008). Between ethnic separation and assimilation: German immigrants and their athletic endeavours in their New American home country. The International Journal of the History of Sport, 25(7), 993-1009.

Institute for Canadian Citizenship. (2014). Playing together: New citizens, sports and belonging. Retrieved from https://www.icc-icc.ca/en/insights/docs/sports /PlayingTogether\%20Full\%20Report.pdf

Joseph, J. (2005). Capoeira in Canada: Brazilian martial art, cultural transformation, and the struggle for authenticity (Unpublished Masters thesis). University of Toronto.

Joseph, J. (2016). Sport in the Black Atlantic: Cricket, Canada and the Caribbean diaspora. Manchester, UK: Manchester University Press.

Karlis, G. (2015). Sport and community building: The case of an ethnic community organization. Loisir et Société/Society and Leisure, 38(2), 239-248.

Krouwel, A., Boonstra, N., Duyvendak, J. W., \& Veldboer, L. (2006). A good sport? Research into the capacity of recreational sport to integrate Dutch minorities. International Review for the Sociology of Sport, 41(2), 165-180.

Kymlicka, W. (2010). The rise and fall of multiculturalism? New debates on inclusion and accommodation in diverse societies. International Social Science Journal, 61(199), 97-112.

Lee, Y., \& Funk, D. C. (2011). Recreational sport participation and migrants' acculturation. Managing Leisure, 16, 1-16.

McNeill, M., Sproule, J., \& Horton, P. (2003). The changing face of sport and physical education in postcolonial Singapore. Sport, Education and Society, 8(1), 35-56.

Meer, N., \& Modood, T. (2012). How does interculturalism contrast with multiculturalism? Journal of Intercultural Studies, 33(2), 175-196.

Nakamura, Y. (2009). Boundaries of belonging: Overlapping loyalties and multiple attachments, a study of the North American Chinese Invitational Volleyball Tournament (Unpublished doctoral thesis). University of Toronto.

Nakamura, Y. (2012). Playing in Chinatown: A critical discussion of the nation/sport/citizen triad. In J. Joseph, S. Darnell, \& Y. Nakamura (Eds.), Race and sport in Canada: Intersecting inequalities (pp. 213-236). 
Toronto, ON: Canadian Scholar's Press, Inc.

Nakamura, Y. (2016). Rethinking identity politics: The multiple attachments of an 'exclusive' sport organization. Sociology of Sport Journal, 33(2), 146-155. doi:http://dx.doi.org/10.1123/ssj.2015-0062

Okay, C. (2003). Sport and nation building: Gymnastics and sport in the Ottoman State and the Committee of Union and Progress, 1908-18. International Journal of the History of Sport, 20(1), 152-156.

Phillips, D., Athwal, B., Robinson, D., \& Harrison, M. (2014). Towards intercultural engagement: Building shared visions of neighbourhood and community in an era of new migration. Journal of Ethnic and Migration Studies, 40(1), 42-59.

PMP, \& Institute of Sport and Leisure Policy. (2004). Studies on education and sport. Sport and multiculturalism. A final report. Retrieved from http://www.iscaweb.org/files/Sport\%20and\%20Multiculturalism\%20 EU\%202004.pdf

Putnam, R. (2000). Bowling alone: The collapse and revival of American community. New York, NY: Simon \& Schuster.

Raman, P. (2015). 'It's because we're Indian, innit?' Cricket and the South Asia diaspora in post-war Britain. Identities: Global Studies in Culture and Power, 22(2), 215-229.

Ricatti, F., \& Klugman, M. (2013). 'Connected to something': Soccer and the transnational passions, memories and communities of Sydney's Italian migrants. The International Journal of the History of Sport, 30(5), 469-483.

Spaaij, R. (2015). Refugee youth, belonging and community sport. Leisure Studies, 34(3), 303-318.

Srivastava, S. (2007). Troubles with anti-racist multiculturalism: The challenges of anti-racist and feminist activism. In S. Hier, \& B. S. Bolaria (Eds.), Race and racism in 21st century Canada: Continuity, complexity, and change (pp. 291-311). Peterborough: Broadview Press.

Statistics Canada. (2010). Projections of the diversity of the Canadian population, 2006 to 2031. Retrieved from www.statscan.gc.ca/pub/91-331-x2010001eng.pdf

Statistics Canada. (2016). Immigration and ethnocultural diversity in Canada. 2011 National household survey. Retrieved from https://www12.statcan.gc.ca/nhsenm/2011/as-sa/99-010-x/99-010-x2011001-eng.cfm
Taylor, T., \& Toohey, K. (1998). Negotiating cultural diversity for women in sport: From assimilation to multiculturalism. Race, Ethnicity and Education, 1(1), 75-91.

Thangaraj, S. (2013). Competing masculinities: South Asian American identity formation in Asian American basketball leagues. South Asian Popular Culture, 11(3), 243-255.

Thangaraj, S. (2015a). Desi hoop dreams: Pick up basketball and the making of Asian American masculinity. New York, NY: New York University Press.

Thangaraj, S. (2015b). 'Liting it up:' Indo-Pak basketball and finding the American-ness in South Asian American instutions. In C.R. King's (Ed.), Asian American athletes in sport and society (pp. 47-66). New York, NY: Routledge.

Theeboom, M., \& Schailée, H., \& Nols, Z. (2012). Social capital development among ethnic minorities in mixed and separate sport clubs. International Journal of Sport Policy and Politics, 4(1), 1-21.

Tirone, S. (2001). Growing up within two cultural traditions: The lives and leisure of Canadian South Asian teens. In J. Anderson \& L. Lawrence (Eds), Gender issues in work and leisure (pp. 67-74). London: Leisure Studies Association Publication.

Tirone, S., \& Pedlar, A. (2000). Understanding the leisure experience of a minority ethnic group: South Asian teens and young adults in Canada. Society and Leisure, 23(1), 145-169.

Toohey, K., \& Taylor, T. (1997). Sport provision for women of minority cultures in Australia: whose responsibility? Women's Sport and Physical Activity Journal, 6(2), 254-264.

Vermeulen, J., \& Verweel, P. (2009). Participation in sport: bonding and bridging as identity work. Sport in Society, 12(9), 1206-1219.

Walseth, K. (2016). Sport within Muslim organizations in Norway: Ethnic segregated activities as arenas for integration. Leisure Studies, 35(1), 78-99.

Wenger, E. (1998). Communities of practice: Learning, meaning and identity. Cambridge: Cambridge University Press.

Willms, N. (2010). Japanese-American basketball: Constructing gender, ethnicity, and community (Unpublished doctoral dissertation). University of Southern California.

\section{About the Authors}

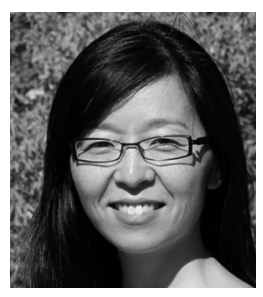

Yuka Nakamura is an Assistant Professor in the School of Kinesiology and Health Science (York University). She studies how race, class, and gender, impact people's identities and physical cultural experiences. Dr. Nakamura is especially interested in sport organized along ethnic, religious, or other 'exclusive' lines, the implications for community building, how terms of inclusion and membership are (re)defined, and how racism and other forms of oppression operate. 


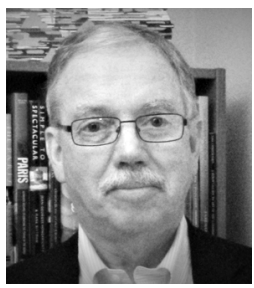

Peter Donnelly is Director of the Centre for Sport Policy Studies, and a Professor in the Faculty of Kinesiology and Physical Education, at the University of Toronto. He was Editor of the Sociology of Sport Journal (1990-94), and Acting-Editor of the International Review for the Sociology of Sport (2004-06); and he is the lead investigator of the project on which this article is based. 